\title{
Regression Towards The Mean Versus Efficient Market Hypothesis: An Empirical Study
}

H. Francis Bush, (Email: bushhf@vmi.edu), Virginia Military Institute Michael D. Canning, (Email: canningmd@vmi.edu), Virginia Military Institute

\begin{abstract}
This study investigates the dominance of the statistical phenomenon, regression towards the means, against the market efficiency of capital markets. Using Fortune Magazine's ranking of America's most admired companies to distinguish positive from negative firms, and using the Standard and Poor Index as a surrogate for market, the authors demonstrated that: (1) a portfolio of least admired forms will outperform a portfolio of most admired firms, (2) a portfolio of most admired firms will outperform the market, and (3) a portfolio of least admired firms will outperform the market.
\end{abstract}

\section{INTRODUCTION}

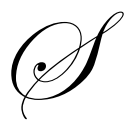

tatistics play an important role as a research tool as evidenced by its use in many areas in business and science. Regression towards the mean is a concept in probability and statistics. It essentially means that, if left alone, an observation that is distant from the mean will, over time, move back toward the mean. If this is the case, then the mean of a sample of stocks that are outperforming the mean population of stocks should begin to decline towards the population mean. On the other hand, the mean of a sample of stocks that are performing below the population mean should rise towards the mean of the population. Regression towards the mean can only occur when the linear relationship between the items is not perfect.

In the capital market, each portfolio of stocks can be considered a sample. Consequently, if regression towards the mean holds true, the mean return on a portfolio of above average firms will fall towards the population mean, producing a return on the portfolio below that of the market. A portfolio of under-performing stocks, however, will act in just the opposite way. The return on such a portfolio should provide a return above the market.

The hypothesis that will be tested in this research project is that the portfolio of under-performing stocks will give a higher return on investment than the high-performing portfolio. The mean return of the high-performing portfolio will fall towards the mean return of the population of stocks, and the mean return of the low-performing portfolio will rise towards the mean return of the population stocks. The research will not be conducted simply to determine that regression towards the mean exists; regression towards the mean has been observed since Sir Francis Galton coined the term in 1875. Rather its practical application in the field of investing will be tested.

The remainder of the paper is organized as follows. The second section will give a literary review of various subjects pertinent to the research. The third section will then show the methodology used. The fourth section will give results from the data collection, which will be displayed and explained. The final section will draw conclusions, as well as describe limitations and areas for future research.

\section{LITERATURE REVIEW}

Portfolio management is the act of controlling the allocation of assets so that an optimal return on investment is accrued over a period of time. It is not just a single, solitary act, but rather a dynamic process under which conditions of markets, interest rates, the investor's goals and skills, and many other factors are constantly monitored to 
ensure that the portfolio of assets is as profitable as possible. Although stocks, on average, make up nearly one-fifth of an individual's net worth, only twenty percent of individuals actually decide in which securities to invest. The portfolios in this research consist of only stocks. The portfolio management strategies described will involve only the stocks.

The goal of investing is to make, or at the very least, preserve money. This applies to every individual or institutional investor. How much, how often, and for how long are the ultimate questions that separate investors from one another. An investor must ask these questions before making any sort of substantial investment. The profits or gains made from investing are called return on investment (ROI). ROI is a tool that enables individuals to effectively analyze the success of an investment. ROI is calculated by the following formula:

\section{(Investment Resale Value + Returns - Investment Cost) Investment Cost}

ROI number is the percentage of the original investment that has been gained back by the investor. In order to make an above average ROI, the investor must have a strategy which is better than the majority of investors. Otherwise, only market returns will be gained. Depending on the type of investment one makes, a high ROI may be returned in a short period of time, or a low ROI may be returned over a long period of time. The ultimate goal of investing is to obtain a strong ROI over a long period of time.

Maginn and Tuttle (1983) developed a flow chart (See Figure 1.) describing the process of developing a portfolio management strategy. First, investors must choose a fundamental strategy for investing. Choosing a strategy is one of the most important decisions to the investor, much more so than simply choosing in which stocks to invest, since the overall strategy for investing will determine which stocks to buy, sell, and when to buy and sell. This philosophy can change over time to fit investors' needs more suitably, or can be left alone if they are satisfied with their return on investment. Deciding which strategy to use can be difficult and confusing for investors, especially if they have very limited access to resources and information.

Figure 1

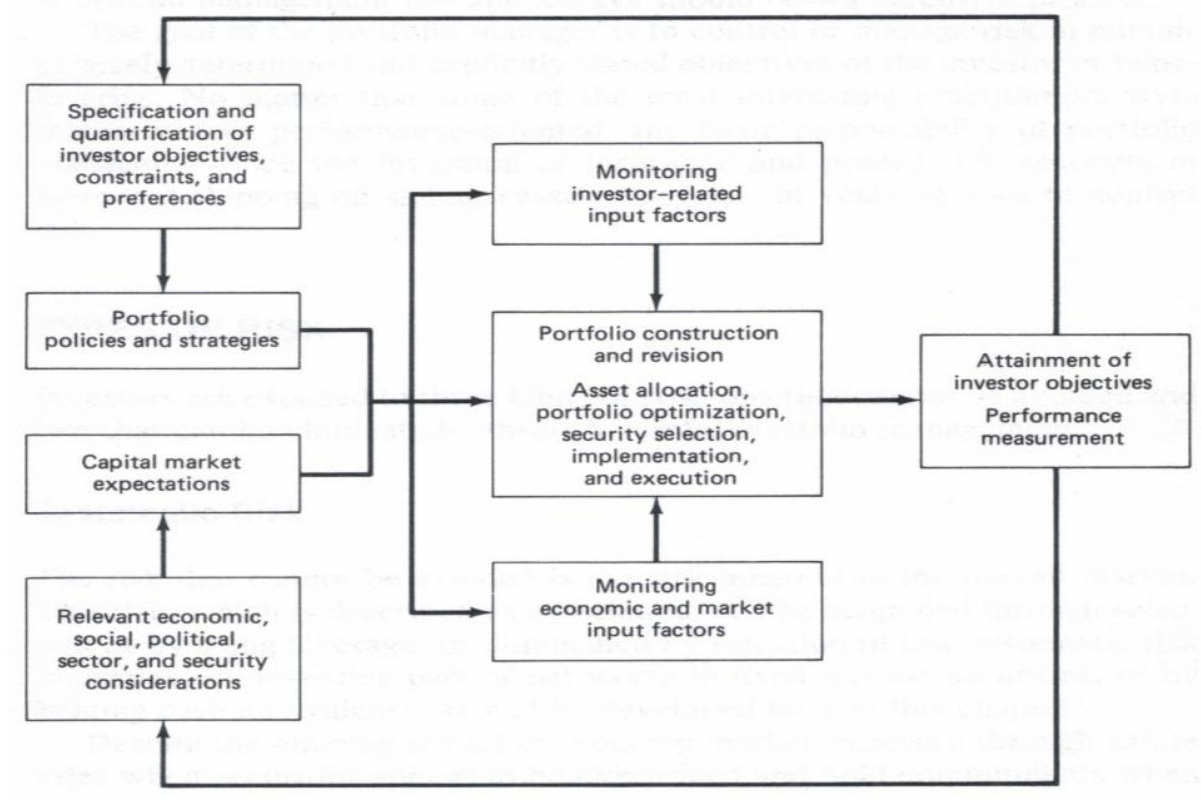

Source: Maginn and Tuttle, Principles of Financial Asset Management, Managing Investment Portfolios, 1983 , pg 9. 
Keith Ambachsheer (1972) developed a chart (See Figure 2.) that may help the investor begin to develop a strategy for investing. The chart below is adapted by Cohen et al. (1982). Two main types of fundamental strategies are represented in the chart. Typical active portfolio management and passive portfolio management can be seen in the upper left and lower right corners, respectively. It would be common for investors to seek a mix between these two strategies based on their specific skills. These strategies can be found in the lower left and upper right corners of the chart. Once again, it should be noted that an investor who is good at forecasting the market and selecting stocks can still make above average returns on investments by using a passive strategy as well as the active strategy presented.

Figure 2

\begin{tabular}{|c|c|c|c|}
\hline & \multicolumn{2}{|c|}{ Ability to Forecast Overall Market } \\
\hline & & Good & Poor \\
\hline \multirow{2}{*}{ 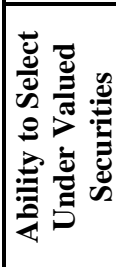 } & $\begin{array}{l}\overrightarrow{8} \\
0 \\
0\end{array}$ & $\begin{array}{l}\text { 1. Concentrate holdings in selected undervalued } \\
\text { securities rather than diversify } \\
\text { 2. Shift beta above and below desired long-term } \\
\text { average, based on market forecasts }\end{array}$ & $\begin{array}{l}\text { 1. Concentrate holdings in selected undervalued } \\
\text { securities rather than diversify } \\
\text { 2. Keep beta stable at desired long-term average }\end{array}$ \\
\hline & 官 & $\begin{array}{l}\text { 1. Hold a broadly diversified list of securities } \\
\text { 2. Shift beta above and below desired long-term } \\
\text { average, based on market forecasts }\end{array}$ & $\begin{array}{l}\text { 1. Hold a broadly diversified list of securities } \\
\text { 2. Keep beta stable at desired long-term average }\end{array}$ \\
\hline
\end{tabular}

Source: Adapted from Keith Ambachsheer

Ibboton and Brinson (1987) indicated that an active portfolio manager must be able to forecast the market more accurately than the other participants in the market to achieve any gains above average. Active management involves taking advantage of the market whenever possible. The active portfolio manager is constantly assessing and updating the portfolio. This portfolio manager feels that it is possible to determine buy and sell points, and that it is possible to find mispriced stocks. The practice of finding and taking advantage of mispriced stocks is called arbitrage. Arbitrage is based on the inefficiencies in the market.

The performance of a portfolio actively managed by the investor will be more heavily weighted on skill and scope than in a passively managed portfolio. An active portfolio manager attempts to take advantage of the market by selection and timing. Selection deals with which stocks to buy or sell, and timing is the decision of when to buy or sell these stocks. Selection and timing are not mutually exclusive, but rather must work together. The real goal of active portfolio management is to find the exceptions within the market. When the averages increase, most stocks will also increase. However, there will be exceptions. Possibly the most difficult part of investing using an active management strategy is attempting to differentiate the stocks that will rise above the average from those that will fall below it.

Passive portfolio management (also called index investing), on the other hand, involves carefully selecting the stocks to be included in the portfolio, then making only minor adjustments to the portfolio throughout the long-run period. The passive portfolio manager will want to create a well-diversified portfolio to eliminate as much risk as possible. While it may be made up of very risky stocks, if well-diversified, the portfolio as a whole will not be risky. Passive portfolio management suits those that have high transaction costs and little or no time to perform research. Index investing is also the choice for those investors wary of risk. Under some schools of thought, no matter how often an active investor buys and sells securities, the investor would be better off just letting the portfolio alone and waiting patiently as stocks will rise.

\section{Efficient Market Hypothesis}

An ideology supporting the use of a passive portfolio management strategy is the Efficient Market Hypothesis (EMH). In a perfectly efficient market, there are four conditions that must be met. First, information must be provided freely and instantaneously. Second, there are no costs associated with trading. Third, actions taken by the individual cannot affect market price. Fourth, it must be assumed that investors maximize utility. In such a market, an 
individual must diversify his portfolio to eliminate unnecessary risk, select an acceptable risk level, and finally determine which stocks fit the investor's needs most closely. Under EMH, an investor would make more money, in the long run, using a passive investing strategy rather than using a speculation strategy, actively buying and selling stocks on a regular basis.

Peter Bernstein (1985) suggested that it is preferable to believe EMH holds true than to believe that it does not. If an individual believes that the market is not efficient when in fact it is, active portfolio managers will then suffer a lower return on investment. However, if an individual believes that the market is efficient and is wrong, then the worst that could happen would be that the portfolio would provide returns equal to the market, and the investor suffers only an opportunity cost. The efficient market hypothesis does not merely attempt to be a description of today's market, but rather it is intended to be an attempt to quantify the market so that investment decisions can be made more easily and accurately. An efficient market would mean that the return from the high performing portfolio would equal the returns from the low performing portfolio because of adjustments in the trading values (prices) of the firms' securities.

\section{Introduction To Risk}

Markowitz (1952) developed a ground-breaking theory: "risk and return are inextricably linked." To obtain a certain ROI, an investor would have to undertake a specified level of risk. Markowitz defined risk as the standard deviation of return. There are two kinds of risk associated with equities and portfolios. The first of these is diversifiable risk, otherwise known as unsystematic or specific risk. This type of risk is not rewarded by the market, since it can be eliminated through simple diversification. The second type of risk is non-diversifiable risk, also known as systematic or market risk. Systematic risk is rewarded by the market since it cannot be eliminated by any means the investor may take; it is inherent in the stock itself. Maginn and Tuttle make an analogy so that these risks are easier to understand. For example, you may pay a fireman a risk premium (danger pay) but be unwilling to pay an additional premium for his running into a burning house naked and without equipment. The argument is that the market does not pay for risks that can sensibly be eliminated. Here, the danger pay is the reward for the (systematic) risk inherent in the job of firefighting.

\section{Risk and Returns}

Markowitz decided that there were three measures that could be used to link returns and risk. The first of these is expected return, which is a weighted average return based on probability. A stock is given probabilities of possible outcomes, and then a weighted average is determined to give a best possible estimate as to the amount a given equity will return for a given period. The second measure used to link return and risk is variance/standard deviation. Standard deviation is able to account for probability of outcomes, range of outcomes, as well as the probability of returns varying from the expected return. Once again, standard deviations and variances are weighted for probabilities. To find variance and standard deviation, a simple equation is used:

$\sum \mathrm{P}_{\mathrm{i}}\left\{\mathrm{N}(\mathrm{R})_{\mathrm{i}}-\mathrm{E}(\mathrm{R})_{\mathrm{i}}\right\}^{2}=\mathrm{PWV} \quad \sqrt{ } \mathrm{PWV}=\mathrm{PWSD}$

where: $P$ is the probability of occurrence for each scenario, $N(R)$ is nominal returns, $E(R)$ is expected returns, $P W V$ is the probability weighted variance, and PWSD is the probability weighted standard deviation.

The expected return subtracted from the nominal return is also called the deviation around expected return. Standard deviation allows for both positive and negative outcomes, as returns tend to follow a normal distribution. It is possible, however, to allow for only positive and negative outcomes, simply by only using the subset of probabilities that the investor wishes to view.

The third measure between risk and returns is covariance/correlation. Covariance measures the degree to which two individual securities move together. 
$\operatorname{COV}(\mathrm{A}, \mathrm{B})=\sum \mathrm{P}_{\mathrm{i}}\left[\mathrm{N}(\mathrm{R})_{\mathrm{i}}-\mathrm{E}(\mathrm{R})_{\mathrm{i}}\right]$

where: $P$ is the probability of occurrence for each scenario, $N(R)$ is nominal returns, and $E(R)$ is expected returns.

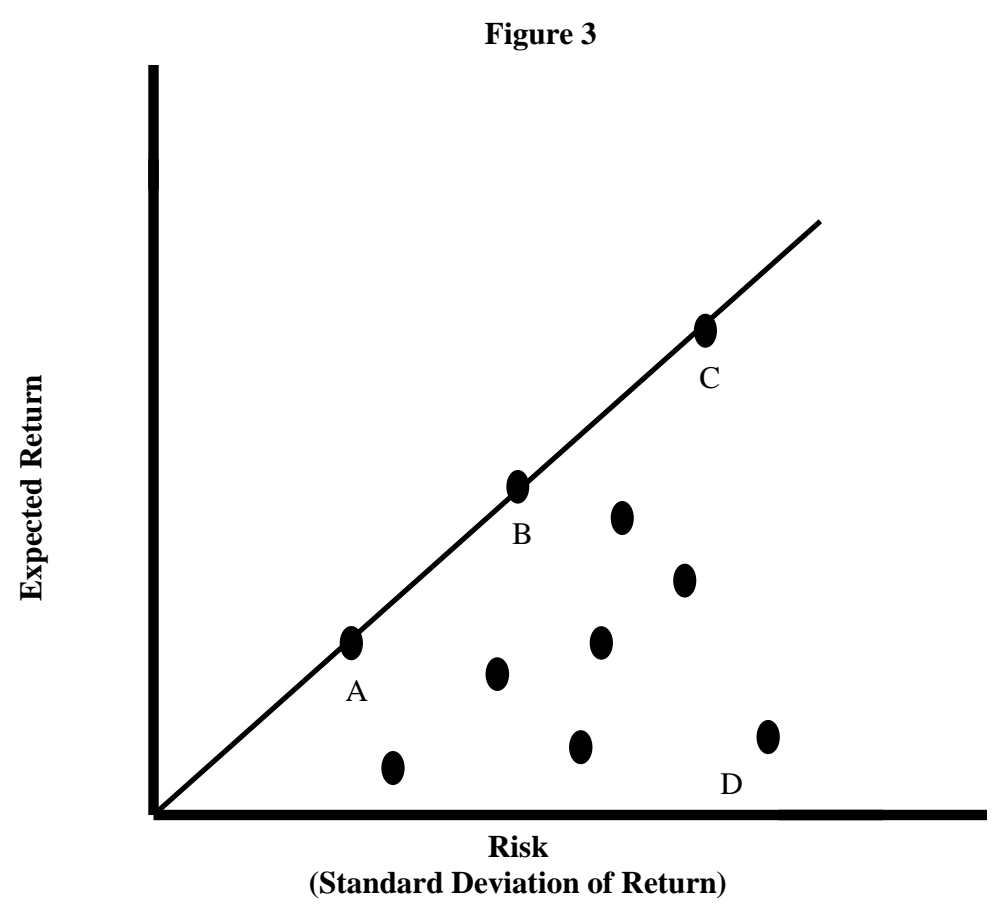

To create the most diversified portfolio possible, each covariance, for each combination of securities possible, would be 0 . Additionally, the investor would want to have stocks from a large number of firms in this portfolio. The more stocks in the portfolio, the lower the percentage of stocks that would suffer should a downturn occur in some sector of the market or the economy as a whole. This ensures that no matter what happens to one stock, the others remain unaffected, and perform based on their own merits and not on the increases and decreases for other stocks. Unfortunately, this efficiently diversified portfolio can only produce mediocre results, as it most likely will follow the market exactly. One of the drawbacks of Markowitz's theory is that it is necessary to find the covariance for each possible combination of securities in the portfolio, which can be fairly time-consuming.

\section{The Efficient Frontier}

Maginn and Tuttle explain that each investor needs to determine the maximum amount of risk acceptable. For each level of risk, the investor should gain a specific amount of return. If an investor is earning the maximum amount of ROI for a given a beta, the investor is said to be on the efficient frontier. Figure 3 is a general depiction of the efficient frontier model. It was originally developed and described by Markowitz. In all likelihood, most efficient frontiers would not be a straight line, but for our purposes, this simplification is sufficient.

Figure 3 is a graphical depiction of the efficient frontier. Each point represents a security. Security A has a relatively low risk, but since it falls on the efficient frontier, it has a higher expected return than other securities of similar risk and lower risk than securities of similar return. Security $\mathrm{C}$ has the highest expected return, but not an inappropriate risk level since it also falls on the efficient frontier. Security D has the most risk, but does not have anywhere near the expected return an investor would desire, since it lies below the efficient frontier. 


\section{Beta}

Sharpe (1963) defined risk as the correlation between two separate price movements, and called this quantification of risk beta $(\beta)$. This greatly simplifies Markowitz's theory utilizing the calculation of many different covariances. Sharpe said that if a certain security moves twice as far as the market does, it is given a beta of 2 . If it moves only $80 \%$ as far as the market, it is given a beta of .8. The higher the beta of a given stock, the more risk it will have. A good measure of performance for a portfolio manager is his ability to gain as much ROI for a given risk level. Beta, however, is not the end-all, tell-all of the performance or future performance of a given stock. Instead, it must be used in conjunction with other tools the investment manager may have.

Elton and Gruber (1981) give a few equations that are useful when attempting to determine how risk affects the return on an investment:

$R_{i}=a_{i}+\beta_{i} R_{m} \quad$ or $\quad R_{i}=\alpha_{i}+\varepsilon_{i}+\beta_{i} R_{m}$

In this equation $a_{i}$ is the component of a security's return that is independent of the market's performance. The expected value of $a_{\mathrm{i}}$ is $\alpha_{\mathrm{i}}$. The random component of $a_{\mathrm{i}}$ is $\varepsilon_{\mathrm{i}}$, or simply put, $\varepsilon_{\mathrm{i}}$ is the difference between $\mathrm{a}_{\mathrm{i}}$ and $\alpha_{\mathrm{i}}$. In most cases, the expected value of $\varepsilon_{\mathrm{i}}$ is assumed to be zero. To be able to estimate $\beta_{\mathrm{i}}$ it is necessary to look at historical betas and see not only how the stock has differed from the market in the past, but also how the betas themselves have fluctuated. To determine the $\beta$ for an entire portfolio, the only action required is to determine a weighted average of the individual betas contained in the portfolio. The equation to find the weighted average is

$\beta_{\mathrm{p}}=\sum\left(\mathrm{N}_{\mathrm{i}} \beta_{\mathrm{i}}\right)$

Where: $\mathrm{N}_{\mathrm{i}}$ is the percent invested for each security and $\beta_{\mathrm{i}}$ is the risk for each security. $\mathrm{N}_{\mathrm{i}}$ was .1 for every stock involved in the research, since each stock makes up $10 \%$ of the portfolio it is in.

\section{Diversification}

Even though the investor may have many stocks with high betas, if the portfolio is well diversified, it is possible to have a conservative portfolio. For example, if the investor holds one high-risk stock in ten different, unrelated industries, his portfolio is fairly well diversified. Even though some of those industries (and therefore the stocks) will struggle and come up short of expectations, the likelihood of all of the industries struggling and producing sub-par returns is not quite as high. Diversification is widely regarded as being the safest way to invest.

\section{Hypotheses}

Portfolio management is an intricate process. It incorporates many variables into decision-making. Our research will include most of these variables in the application of regressions towards the mean to the investment decision. There are two positions available to investors, the EMH and regression towards the mean (RTM). If in fact EMH holds true, then a portfolio of stocks from most admired companies would have the same return as a portfolio of stocks from least admired companies. If EMH were false however, then RTM would be the determining factor in return on investment. RTM would imply that a portfolio of stocks below the mean would create a higher return than a portfolio of stocks that are above the mean. Thus, the following hypotheses will be tested:

$\mathbf{H}_{\mathbf{0}}$ : $\quad$ The mean ROI will be equal for both portfolios. (EMH)

$\mathbf{H}_{1}$ : The mean ROI will be higher for the portfolio of stocks from the least admired firms. (RTM)

$\mathbf{H}_{0}$ : The mean ROI of the most admired firms will be equal to Standard and Poor's. (EMH)

$\mathbf{H}_{1}$ : $\quad$ The mean ROI of the most admired firms will be less than Standard and Poor's. (RTM)

$\mathbf{H}_{0}$ : The mean ROI of the least admired firms will be equal to Standard and Poor's. (EMH)

$\mathbf{H}_{1}$ : The mean ROI of the least admired firms will be greater than Standard and Poor's. (RTM) 


\section{METHODOLOGY}

\section{Data}

Tittermary (2005) collected data from the Wall Street journal on approximately 200 companies from 1983 through 2000. Similar to the methodology used by Clayman (1987), Tittermary gathered stock prices out five years from the top ten and bottom ten of the Most Admired lists. When some company prices were unavailable, Tittermary excluded those companies from the calculations for that year.

\section{Return On Investment}

Return on investment was calculated for each portfolio as:

$\underline{\mathrm{ROI}}=\sum\left(\mathrm{SHS}_{\mathrm{ic}}\right)(\mathrm{CP})+$ Dividends Issued $-\sum\left(\mathrm{SHS}_{\underline{\mathrm{i}}}\right)(\mathrm{OP})$ $\sum\left(\mathrm{SHS}_{\mathrm{io}}\right)(\mathrm{OP})$

Where: $\mathrm{SHS}_{\mathrm{ic}}$ are the amount of shares at closing price, CP is the closing price, $\mathrm{SHS}_{\mathrm{io}}$ is the amount of shares at the opening price, and OP is the opening price.

\section{RESULTS}

\section{Descriptive Statistics}

For each year, three differences were calculated after one year, two years, and after three years. Subtracting the return of the top-ten portfolio from the return of the bottom-ten portfolio provides a difference that is anticipated to be positive if the null hypothesis is rejected. Similarly, subtracting the Standard and Poor's returns from the top ten portfolio is anticipated to be negative and subtracting the Standard and Poor's return from the bottom ten portfolio is anticipated to be positive if the null hypothesis is rejected in favor of regression toward the mean. A summary of the descriptive statistics can be found in Table 1.

\section{The t-Test}

Because of the small sample size, a t-test was necessary to accurately assess the data set. Further, the differences are assumed to be distributed approximately normal. The test used was a matched pair sample. The matched pair test is used when data collected from two separate populations are correlated under some parameter. In this case, the two populations were the top-ten portfolios and the bottom-ten portfolios. The parameter used to connect them was the year in which each portfolio was taken. To perform the matched pair t-test, the difference between the bottom-ten and top-ten returns were used and an average taken. The t-statistics are presented in Table 2.

Table 1

\begin{tabular}{|l|c|c|c|c|c|c|}
\hline & \multicolumn{3}{|c|}{ Average Difference } & \multicolumn{3}{c|}{ Standard Deviation } \\
\hline Years Later & 1 & 2 & 3 & 1 & 2 & 3 \\
\hline Least Admired Portfolio - Most Admired & 8.45 & 12.21 & 9.48 & 23.28 & 39.26 & 26.85 \\
\hline Most Admired Portfolio - S\&P & 0.34 & 1.03 & 1.34 & 1.45 & 2.28 & 2.56 \\
\hline Least Admired Portfolio - S\&P & 8.78 & 13.24 & 10.82 & 22.69 & 38.26 & 25.42 \\
\hline
\end{tabular}

Table 2

\begin{tabular}{|l|c|c|c|}
\hline & \multicolumn{3}{|c|}{ t-Statistics } \\
\hline Years Later & 1 & 2 & 3 \\
\hline Least Admired Portfolio - Most Admired & $1.45^{* *}$ & 1.24 & $1.41^{* *}$ \\
\hline Most Admired Portfolio - S\&P & 0.93 & $1.82^{*}$ & $2.09^{*}$ \\
\hline Least Admired Portfolio - S\&P & $1.55^{* *}$ & $1.55^{* *}$ & $1.70^{* *}$ \\
\hline
\end{tabular}


The results are mixed. When comparing the portfolio of least admired firms to either the portfolio of most admired firms or to the Standard and Poor's return, the null hypothesis of efficient hypothesis is rejected at $\alpha=.10$ in five of the six tests. However, when the portfolio of most admired firms is compared to the Standard and Poor's return, the sign of the difference is positive. Further, the t-statistic would have been significant at $\alpha=.05$. These values would be sufficient to reject the regression towards the mean hypothesis in favor of the efficient market hypothesis.

\section{CONCLUSION, LIMITATIONS, AND FUTURE RESEARCH}

\section{Conclusion}

The results were quite surprising. Although, the data for the firms which were least admired are consistent with the theory that regression towards the mean will affect the movement of portfolios' return, it is not consistent for firms which were most admired. However, for firms that were most admired, the results were all significant enough to reject the null hypothesis of an efficient market as well as regression towards the mean. Averages can disguise individual occurrences. These statistics show that while, as a whole, the efficient market hypothesis can be rejected, in individual years this is far from reality. This leaves open the opportunity for investors to make larger ROI's by using arbitrage.

\section{Limitations}

There are a few possible reasons for the results. First, simply, regression towards the mean does not apply evenly in the investing environment. Second, there could be flaws in the samples chosen for the research. Just because the company is high on the Fortune 500 most admired firms list does not mean that its stock is above the mean return of the population of all stocks. The same can be said of the bottom-ten portfolios. Third, our high/low approach may not have been appropriate. It is possible that the extremes of our portfolios, relative to the mean, were not able to display regression towards the mean effectively. A portfolio closer to the mean may have a better chance of exhibiting such properties.

\section{Future Research}

To verify the sampling, portfolios could be developed at the 100, 200, 300, and 400 levels within the Fortune 500. Each portfolio would be composed of ten companies ranked within five of the new cutoffs. The additional samples would provide a greater opportunity to demonstrate if regression towards the mean played any sort of part in the movement of these portfolios. Overall, even though the results of the research were not conclusive, they were not irrelevant. In the future, more research can be conducted to produce more conclusive results on whether regression towards the mean or the efficient market hypothesis influences the return of portfolios.

\section{Acknowledgement}

Authors gratefully acknowledge Michael Tittermary's willingness to share his data for this analysis.

\section{REFERENCES}

1. America's Most Admired Companies. Fortune Magazine. January 1983 - March 2003 (multiple issues).

2. Ambachtsheer, Keith. Portfolio Theory and the Security Analyst. Financial Analysis Journal. (November December 1972). pp 53-57.

3. Bernstein, Peter L. Pascal's Wager and the Efficient Market Hypothesis. Journal of Finance. (July 1985). p.1.

4. Clayman, Michelle. In Search of Excellence: The Investor's Viewpoint. Financial Analysts Journal. (MayJune 1987). pp 54-63.

5. Cohen, Jerome B., Arthur Zeikel, and Edward D. Zinbarg. Investment Analysis and Portfolio Management. Homewood, Illinois: Richard D. Irwin, Inc., 1982. 
6. Elton, Edwin J. and Martin J. Gruber. Modern Portfolio Theory and Investment Analysis. Second Edition. New York: John Wiley \& Sons, Inc., 1981.

7. Hagstrom, Robert G. The Essential Warren Buffett. New York: John Wiley \& Sons, Inc., 2001.

8. Ibbotson, Roger G. and Gary P. Brinson. Investment Markets: Gaining the Performance advantage. New York: McGraw-Hill. (1987).

9. $\quad$ Krass, Peter, ed. The Book of Investing Wisdom. New York: John Wiley \& Sons, Inc., 1999.

10. Maginn, John L. and Donald L. Tuttle, eds. Managing Investment Portfolios. Boston: Warren, Gorham, \& Lamont, 1983.

11. Markowitz, Harry. Portfolio Selection. The Journal of Finance. (March 1952). pp 77-91.

12. Radcliffe, Robert C. Investment Concepts, Analysis, and Strategy. Dallas: Scott, Foresman, and Company, 1982.

13. Reilly, Frank K. Investment Analysis and Portfolio Management. Chicago: Dryden Press, 1985.

14. Sharpe, William F. A Simplified Model for Portfolio Analysis. Management Science. (January 1963. pp 277).

15. Tittermary, Michael. Market Pricing Efficiency: Does Fortune Magazine's "Most Admired" Ranking Cause a Stock Market Anomaly? Academy of Economics and Finance 2005 Meeting. February, 2005.

\section{$\underline{\text { NOTES }}$}


NOTES 